\title{
The impact of Brexit on oral health
}

\author{
James Coughlan ${ }^{1}$ and Sam Shah*2
}

\section{Key points}

Explains the role of the European Union in relation to oral health in the UK.
Highlights the potential effects of Brexit on oral health and oral healthcare in the UK.
Suggests how practitioners can prepare for potential effects of Brexit.

\begin{abstract}
Introduction The United Kingdom (UK) left the European Union (EU) on 31 January 2020. Brexit will impact many sectors of the economy, including the dental sector.

Methods and analysis This policy analysis evaluates UK and EU legislation and planning documents, as well as the published literature, to analyse the impact of two scenarios relating to the UK's exit from the EU on the dental sector: a free trade agreement based on the jointly agreed Political Declaration (the 'FTA') and a 'no-deal' scenario.

Conclusion An FTA could cause price increases of medicines and medical devices, and cause some disruption to the ability of regulating authorities in this area, while a no-deal would additionally risk shortages of medicines and medical devices as well as more dramatic price increases. In both an FTA and a no-deal scenario', with EU law no longer applicable to the UK, more innovative policy in the area of tobacco control could be developed. An FTA could exacerbate existing workforce shortages and would likely cause a reduction in EU research funding, as well as posing issues with data transfers, with these all likely to be more severe under a no-deal scenario.
\end{abstract}

\section{Introduction}

On 31 January 2020, the United Kingdom (UK) ceased to be a member of the European Union (EU) and entered into a yearlong transition period, governed by the Withdrawal Agreement. ${ }^{1}$ The two parties are currently negotiating the future relationship, the ambitions for which were set out in the Political Declaration (PD). ${ }^{2}$ The deadline for a future agreement is 31 December 2020; this includes the main free trade agreement that the Prime Minister, Rt Hon. Boris Johnson $\mathrm{MP}$, has called for in the PD, as well as separate agreements covering UK-EU cooperation in other sectors.

'Institute of Dentistry, Barts and The London School of Medicine and Dentistry, Queen Mary University of London, Turner St, Whitechapel, London E1 2AD; ${ }^{2}$ Specialist in Dental Public Health \& Group Clinical Director, East Village Dental, 3-5 Mirabelle Gardens, London, E20 3BX.

*Correspondence to: Sam Shah

Email address: sam.shah@nhs.net

Refereed Paper.

Accepted 15 July 2020

https://doi.org/10.1038/s41415-020-2278-z
The various incarnations of Brexit and their impact on the health and social care system as a whole have been extensively discussed, ${ }^{3,4,5}$ with most concluding that any form of Brexit could negatively impact the NHS to a greater or lesser extent. There have, however, been very few analyses of the effects of Brexit on dentistry, and previous analysis has focused on a pre-referendum 'remain $v s$ leave' paradigm. ${ }^{6}$

This policy analysis aims to address this gap in the literature and set out the implications for oral health based on two main scenarios - a deal based on the PD, based on 'an ambitious, broad, deep and flexible partnership across trade and economic cooperation with a comprehensive and balanced Free Trade Agreement at its core, law enforcement and criminal justice, foreign policy, security and defence and wider areas of cooperation, ${ }^{2}$ and a no-deal, which is the default legal position if no agreement is reached. We use UK and EU legislation and planning documents, as well as the published literature, to examine how different agreements will impact on oral health in five areas: workforce; access to medicines and medical devices; the right to treatment; public health; and research.

\section{What is being negotiated?}

At the core of the negotiations is a free trade agreement (FTA), which aims to increase the level of trade across borders by reducing or eliminating tariffs (import fees) or quotas on the number of goods (eg medicines) and services (eg medical care) that are traded across the borders. The current positions of the two sides provide a lack of clarity as to the final form of this deal. The EU are calling for 'level playing field' measures to align the UK with single market laws in order to prevent economic measures that would undermine EU competitiveness, with disputes arbitrated by the European Court of Justice (ECJ). ${ }^{7}$ The UK, meanwhile, favours divergence from single market laws in order to strike trade agreements with third countries, with disputes arbitrated outside of the ECJ. ${ }^{8}$ Prime Minister Johnson has made it clear that the UK would leave both the EU's single market and Customs Union. 
Other deals will need to be struck, many pertinent to oral health. These include: agreements on medicine and medical device regulation through affiliation with the European Medicines Agency (EMA); research and innovation policy through the European Research Area (ERA) and the upcoming FP9 framework; data transfers via an EU Commission adequacy decision; and access to public health warning systems through the European Centre for Disease Prevention and Control (ECDC).

Such agreements can be mediated through different means, either through individual arrangements with the relevant EU institution or agency, as part of an overarching political agreement between the EU and the country, or by a combination of both. ${ }^{9}$

The decisions made in the core FTA will have implications for other agreements related to oral health; for example, the ECJ has a role in disputes around research funding, ${ }^{9}$ while single market rules dictate flows of data essential for the functioning of the Early Warning and Response System (EWRS), a communicable disease alert system coordinated by the ECDC and DG SANTE, the health directorate for the EU Commission. ${ }^{10}$

\section{Workforce}

EU and European Economic Area (EEA), which includes Norway, Iceland and Lichtenstein, dentists have traditionally provided a significant supply of labour to the UK dental market, although the absolute number and relative proportion of new registrants has been declining year on year. In 2013, new EEA entrants numbered 666 , representing $30.1 \%$ of new registrants. In 2018, these figures stood at 394 and $22.1 \%$, respectively, although absolute numbers of EEA registrants have stayed relatively constant thanks to fewer leaving the register. ${ }^{11}$ EEA dentists make up $16 \%$ of the workforce and carry out an estimated $22 \%$ of NHS activity, suggesting they are more likely than UK graduates to carry out NHS activity.

A framework of 'push' and 'pull' factors has been utilised to analyse the effect of Brexit on the workforce, exploring recruitment and retention of international healthcare workers to analyse the effect of Brexit on the workforce. ${ }^{12}$ These are summarised in Table 1, alongside Brexit-related factors taken from the General Dental Council (GDC) survey.

These factors will affect how EU and EEA dentists respond to any deal or lack thereof. A GDC survey found that $32 \%$ were considering

Table 1 A framework of 'push' and 'pull' factors alongside Brexit-related factors, adapted with permission from Buchan et al., International nurse mobility: trends and policy implications, 2003, World Health Organisation; ${ }^{12}$ using data from GDC survey of EEA registrants ${ }^{14}$

\begin{tabular}{|c|c|}
\hline Push/pull factors & Relevance to Brexit \\
\hline $\begin{array}{l}\text { Pay difference (absolute and/ } \\
\text { or relative) }\end{array}$ & $\begin{array}{l}\text { Strength of the pound has fallen relative to the euro, making the wage } \\
\text { difference between the UK and many EU27 countries smaller }\end{array}$ \\
\hline Working conditions & $\begin{array}{l}\text { Falling satisfaction of NHS dentists with current working conditions }{ }^{13} \\
\text { Reported better working conditions in other countries }\end{array}$ \\
\hline Resources in health system & $\begin{array}{l}\text { Lack of investment in NHS dental services may make it a less attractive } \\
\text { practising environment }\end{array}$ \\
\hline Career opportunities & $\begin{array}{l}\text { The Department for Health and Social Care has also confirmed that those } \\
\text { qualifications listed in the EU's Professional Qualifications Directive } \\
2005 / 36 / E C \text { will continue to be accepted in the case of a no-deal }{ }^{15}\end{array}$ \\
\hline Educational opportunities & UK specialties will not continue to be recognised by other EU and EEA countries ${ }^{16}$ \\
\hline Travel opportunities & $\begin{array}{l}\text { In the case of no-deal, visa-free travel between the UK and EU would be } \\
\text { limited to } 90 \text { days within } 180 \text { days }^{17}\end{array}$ \\
\hline $\begin{array}{l}\text { Brexit/don't feel welcome/ } \\
\text { economic situation }\end{array}$ & $\begin{array}{l}82 \% \text { of EEA dentists who indicated they wished to leave said that Brexit and } \\
\text { the surrounding issues contributed to their intention to leave the UK }{ }^{14}\end{array}$ \\
\hline
\end{tabular}

leaving, although half of these stated that they would reconsider if mutual recognition of qualifications was assured, which it now has been, ${ }^{15}$ and if most rights currently enjoyed by EU residents would continue even under a no-deal. ${ }^{14,18}$

Many respondents, however, stated that the uncertainty around Brexit was a significant factor in their choice to leave. Considering the uncertainty of the current negotiations, this may tip some towards leaving.

The impact of this on access to oral healthcare will vary by region; there is likely to be limited impact on the workforce in already well-supplied areas such as London and other large cities. There is, however, a worry that the effects in rural and coastal areas risk exacerbating current access issues, as these areas are heavily reliant on the EU workforce, as well as having lower levels of access to NHS dental services and higher levels of need. ${ }^{19}$ The dental education and training agencies in each of the four UK nations will need to consider such shortages in future workforce planning exercises to ensure that regional inequalities in access are not perpetuated.

The EU has stated that, after 1 January 2021, UK nationals or EU citizens holding a UK qualification will be required to have them registered by the Member State's rules for third-country nationals or qualifications. ${ }^{16}$

\section{Access to medicines and medical devices}

Access to medicines and medical devices related to dentistry (such as clinical consumables, dental instruments and implants) will be impacted by two key mechanisms relating to Brexit: 1) costs relating to trade; and 2) regulation and safety surveillance.

Currently, medicines and medical devices can be traded between the EU and UK without tariffs, quotas or non-tariff barriers (such as additional paperwork and border checks), due to the single market and the harmonisation of standards at the EU level. This allows for rapid movement of 82 million packets of medicines between the UK and EU every month. ${ }^{3}$ Medical devices often feature complex supply chains with different parts made in different countries across the EU before assembly.

Regulation of medicines and medical devices is coordinated by the EMA, which carries out a number of activities; it recommends new drugs to be approved for marketing authorisation across the EU, as well as carrying out a pharmacovigilance and vigilance function (the process of post-marketing safety surveillance of medicines and medical devices, respectively) with an alert system if a series of adverse effects are reported. ${ }^{20}$ The assessment of new medications is delegated to National Competent Authorities (NCAs) by the EMA, and these bodies carry out an assessment and make a recommendation. The assessment of medical devices is also done at a national level through the UK's Medicines and Healthcare products Regulatory Agency (MHRA), with some assessments also delegated to private sector 'notified bodies', who can grant a CE mark to allow sale across the EU.

These processes allow resource and expertise pooling across the EU, with the UK's MHRA playing a significant role in the process, leading on $20 \%$ of medicine assessments and $50 \%$ of medical device assessments. 
An FTA would abolish all tariffs on medicines and medical devices, although nontariff barriers such as regulatory border checks and additional paperwork would increase costs to manufacturers ${ }^{21}$ by approximately $12 \%$, according to government modelling. ${ }^{22}$ Such non-tariff barriers could be minimised through regulatory alignment, achieved either through an overarching agreement, such as the EU has with Canada in the EU-Canada Comprehensive Economic and Trade Agreement, or through a separate agreement on 'cooperation', as was alluded to in the PD. ${ }^{2}$

A no-deal would threaten the supply of medicines and medical devices. Ministers and freight industry representatives have highlighted initial delays in supply, due to the closed-loop nature of the ports in Calais and Dover. Prior to the October 2019 agreement, the government had stockpiled six weeks' worth of medicines and medical devices to ease short-term delays in the event of a no-deal, although government risk planning suggests that, in the event of a no-deal, disruptions could last for six months, ${ }^{23}$ putting access to medicines and medical devices at risk. This is compounded by stock shortages from the COVID-19 response.

There has been a suggestion that the UK could continue to allow medical devices with the $\mathrm{CE}$ mark to be imported without additional checks; ${ }^{24}$ however, this would contravene the World Trade Organisation's (WTO's) 'most-favoured nation' rule, which prevents the UK easing checks from one trading partner without doing so for all trading partners, if trading under WTO terms in the case of a no-deal. The UK may be forced to impose customs checks on devices and materials from the EU or to waive checks on medicines and medical devices from other countries, raising the risk of lower-quality or counterfeit products entering the UK undetected, including tooth-bleaching products and handpieces.

If no agreement can be made with regards to EMA affiliation or membership, the UK will lose access to pharmacovigilance and vigilance data, with delays of up to five months in getting safety alerts. ${ }^{25}$ It would also negatively impact the competitiveness of the pharmaceutical industry, with delays in bringing new drugs to market. $^{26}$

\section{Right to treatment}

Currently, under EU law, there is a reciprocal right to access care across the EU while in any of the states. This applies to both UK citizens who are residents of another EU country and those travelling temporarily to another EU country, usually using a European Health Insurance Card (EHIC). In most countries, some basic dental care is available using an EHIC, often through dentists associated with social insurance systems. ${ }^{27} \mathrm{EU}$ citizens can access NHS dental services in the same way as a citizen of the UK.

If a UK citizen is a registered resident in an EU country before 31 December 2020, they will continue to be eligible to access care as citizens of that country would, and vice versa for EU citizens in the UK. ${ }^{28}$ Reciprocal right to healthcare is an area to be determined in negotiations - an area of weakness on the part of the UK given the large number of elderly UK nationals residing in the EU. If no deal is agreed, then it is highly likely that no agreements will be in place immediately. UK nationals will likely face barriers to accessing care, such as paying the full cost of treatment upfront and logistical barriers in being reimbursed. ${ }^{29} \mathrm{EU}$ citizens travelling to the UK would be required to pay for NHS dental services, with hospital dental care being charged at $150 \%$ of the tariff charge. Those settling in the UK would likely be required to pay the NHS surcharge of $£ 400$ per year.

\section{Public health}

Healthcare delivery and organisation is a national competency. Many EU public health functions are therefore carried out through regulatory mechanisms, disease surveillance and health promotion campaigns.

The Tobacco Products Directive (2014/40/ EU) provides a highly regulated market for tobacco-based products, including on the sale and promotion of e-cigarettes. While the longterm risks of vaping are unknown, there is a growing (although not ubiquitous) ${ }^{30}$ consensus that e-cigarettes are less detrimental to health compared to combustible tobacco products and, in certain circumstances, may be used to facilitate smoking cessation. ${ }^{31}$ A parliamentary report found opportunities after Brexit to move towards 'risk-based' regulation and taxation of e-cigarettes by: reducing current taxes levied on them; increasing the minimum nicotine content in order to increase use by those with a high nicotine dependency; and allowing marketing claims of reduced harm relative to tobacco products. ${ }^{32}$ While extensive debate and consultation would be required before enacting such reforms, freedom from the constraints of the Tobacco Products Directive could allow for more innovative policy development in this area.

The ECDC plays a key role in communicable disease surveillance and health, most relevantly to dentistry through its role in coordinating antimicrobial resistance surveillance across states. ${ }^{33}$ It is also jointly responsible for the aforementioned early warning system with DG SANTE. It is highly likely that access to ECDC data and the early warning system will end after Brexit, both being reliant on EU or EEA membership. COVID-19 has highlighted the importance of timely management of disease outbreaks for access to dental care, ${ }^{34}$ demonstrating the importance of accessing early data on outbreaks not only to the medical profession but to the dental profession as well. As Switzerland has found, access to the EWRS is simply unfeasible for non-member states who will not accept single market rules. ${ }^{10}$

\section{Research}

The EU research agenda is delivered primarily through the EU Framework Programmes, which are funding schemes agreed in the EU budget - the Multiannual Financial Framework (MFF). The most recent of these was Horizon 2020, while its successor will be FP9, which will begin once the latest MFF is approved by all member states, likely in 2020 or 2021.

The UK research community has benefited significantly from such programmes, being net recipients of funding awards, as well as non-financial benefits such as driving quality, collaboration and supporting the movement of talented workforce. ${ }^{35}$ There is not a lot of data on the contribution of EU funding sources to dental institutes, but that available from King's College London Dental Institute shows that EU funding sources account for the largest share of their research funding at $30 \%$, amounting to $£ 20$ million. ${ }^{36}$

Access to Horizon 2020 funding is not limited to EU or EEA countries. There is an option to be 'associated' to Horizon 2020, as countries such as Israel, Turkey and Switzerland are. ${ }^{37}$ This could be negotiated in the case of an FTA or a no-deal, but this associated membership is not without political implications. Switzerland's access to Horizon 2020 was withdrawn by the EU for a period of time after their referendum to limit freedom of movement, a policy which was in breach of previous agreements. ${ }^{38}$ Access could be linked to concessions from the UK in other areas, and disputes or difficulties in future negotiations 
could cause uncertainty as to the continuity of funds.

Clinical trials will also be affected postBrexit. The new EU Clinical Trials Regulation 2014 will likely come into force in late 2021 . The government and MHRA have indicated they will seek close alignment with these regulations postBrexit, ${ }^{35}$ but this alone will not automatically ensure the ability to participate in or lead trials, nor allow access to the EU trials register. A weak agreement in this area could prevent UK researchers or companies sponsoring or leading international trials, and would increase the costs and complexity of doing so. ${ }^{35}$

Furthermore, any personal data stored by UK research institutions on servers in EU27 countries, including patient consent forms and personal medical data, would become a 'restricted transfer', as data would be moving from outside the EEA to a third country. ${ }^{39}$ This means that these research institutes would have to make 'appropriate safeguards' to ensure continued access to stored data in the event of a no-deal.

\section{Discussion}

This analysis demonstrates that Brexit will have a significant impact on dentistry and oral health. Most notably, this impact will be on the workforce, the area that has been most prominent in discussions surrounding Brexit and the dental workforce. There has been concern among Health Education England and the GDC that the UK will no long be able to attract sufficient dentists post-Brexit ${ }^{40}$ and that regulation of degrees in the long term will pose significant problems. ${ }^{19}$ Despite this, it is not clear that much has been done to resolve this; training places in dental schools have not been increased, while an increase in capacity for the GDC's regulatory activities has not received further funding.

However, while the workforce is perhaps the largest and most visible aspect of Brexit's effect on access to oral health, other aspects with similarly serious consequences have not been discussed at all, such as access to medicines and medical devices. The fragility of supply chains has been clearly exposed during the COVID-19 crisis, and a so-called 'double hit' of the outbreak of SARS-CoV-2 virus and a no-deal Brexit could limit the availability of dental supplies and essential medicines.

Some have questioned the relevance of Brexit given the disruption that COVID19 has caused; yet, to an already fragile health system with only limited dental care being provided in most parts of the UK, a no-deal or an agreement that does not carefully consider health could further limit the ability of normal dental services to resume.

There is political incentive for both the EU and UK to agree a deal. Despite this, practices and clinics should adequately prepare themselves should no deal be agreed. They should consult their suppliers to ensure adequate supplies of clinical consumables and materials, as well as monitoring availability of medicines in their local area.

Health was mentioned sparsely in the PD, and technical decisions on trade, recognition of qualifications and research will have real impacts on the dental community. Despite the fatigue of many over the Brexit process, those in the dental professions should use their status as health professionals to lobby for dentistry and healthcare to be prioritised going forward in negotiations. Dental policymakers should also evaluate the capacity of the dental profession to respond to different scenarios and ensure that adequate measures are taken to limit the impact. Furthermore, those in the profession should engage not only with the current negotiations on the core deal, but also on negotiations over regulation, research and adequacy decisions.

\section{Conclusion}

This analysis has described and suggested how an FTA based on the PD and a no-deal Brexit would impact access to oral health in the UK. A no-deal could have a detrimental impact, and while an FTA would limit the worst damages, if agreements in other areas are not reached, there could still be a negative impact. Policymakers and regulators across dentistry need to work together to address these factors.

\section{References}

1. UK Government. Agreement on the withdrawal of the United Kingdom of Great Britain and Northern Ireland from the European Union and the European Atomic Energy Community. 2019. Available at https://assets.publishing. service.gov.uk/government/uploads/system/uploads/ attachment_data/file/840655/Agreement_on_the_ withdrawal_of_the_United_Kingdom_of_Great_Britain_ and_Northern_Ireland_from_the_European_Union and_the_European_Atomic_Energy_Community.pdf (accessed October 2020).

2. UK Government. Political Declaration setting out the framework for the future relationship between the European Union and the United Kingdom. Available at https://assets.publishing.service.gov.uk/government/ uploads/system/uploads/attachment_data/ file/840656/Political_Declaration_setting_out_the framework_for_the_future_relationship_between_ the_European_Union_and_the_United_Kingdom.pdf (accessed October 2020)
3. Brexit Health Alliance. Briefing: Brexit and the impact on patient access to medicines and medical technologies. 2018. Available at https://www.hpcimedia.com/ images/PDF/Brexit\%20PDF.pdf (accessed October 2020).

4. Fahy N, Hervey T, Greer $\mathrm{S}$ et al. How will Brexit affect health and health services in the UK? Evaluating three possible scenarios. Lancet 2017; 390: 2110-2118.

5. Fahy N, Hervey T, Greer $S$ et al. How will Brexit affect health services in the UK? An updated evaluation. Lancet 2019; 393: 949-958.

6. Sinclair E, Stagnell S, Shah S. Brexit and dentistry. $\mathrm{Br}$ Dent J 2016; 220: 509-512.

7. European Commission. Recommendation for a council decision authorising the opening of negotiations for a new partnership with the United Kingdom of Great Britain and Northern Ireland. 2020. Available at https://eur-lex.europa.eu/legal-content/EN/ TXT/?uri=CELEX\%3A52020PC0035 (accessed October 2020).

8. Institute for Government. UK-EU future relationship: UK and EU mandates. 2020. Available at https://www. instituteforgovernment.org.uk/printpdf/9510 (accessed October 2020).

9. Wellcome Trust. Building a strong future for European science: Brexit and beyond - Wellcome's recommendations from the Future Partnership Project. 2018. Available at https://wellcome.org/sites/default/ files/building-strong-future-european-science-brexitbeyond.pdf (accessed October 2020).

10. Flear M, De Ruijter A, McKee M. Coronavirus shows how UK must act quickly before being shut out of Europe's health protection systems. BMJ 2020; DOI: 10.1136/ bmj.m400.

11. O'Dowd A. Brexit delay is hurting dentistry recruitment. Br Dent J 2019; 227: 179-182.

12. Buchan J, Parkin T, Sochalski J. International nurse mobility: Trends and policy implications. 2003. Available at https://apps.who.int/iris/bitstream/ handle/10665/68061/WHO_EIP_OSD_2003.3.pdf (accessed October 2020)

13. NHS Digital. Dental Working Hours, 2014/15 and 2015/16 Motivation Analysis, Experimental Statistics. 2016. Available online at https://digital.nhs.uk/ data-and-information/publications/statistical/dentalworking-hours/dental-working-hours-2014-15-and2015-16-motivation-analysis-experimental-statistics (accessed October 2020).

14. GDC. Survey of European Qualified Dental Professionals: Final Report. 2019. Available at https://www.gdc-uk. org/docs/default-source/research/survey-of-europeanqualified-dental-professionals.pdf (accessed October 2020).

15. UK Government. The European Qualifications (Health and Social Care Professions) (Amendment etc.) (EU Exit) Regulations 2019. 2019. Available online at https:// www.legislation.gov.uk/uksi/2019/593/contents/made (accessed October 2020).

16. European Commission. Getting ready for changes: Communication on readiness at the end of the transition period between the European Union and the United Kingdom. 2020. Available at https://ec.europa.eu/info/ publications/getting-ready-changes-communication-readiness-end-transition-period-between-european-union-and-united-kingdom_en(accessed October 2020).

17. European Commission. Notice on travelling between the EU and the United Kingdom following withdrawal of the United Kingdom from the EU. 2018. Available at https://ec.europa.eu/info/sites/info/files/brexit_files/ info_site/travelling.pdf (accessed October 2020).

18. UK Government. No deal immigration arrangements for EU citizens moving to the UK after Brexit 2019. Available online at https://www.gov.uk/government/ publications/no-deal-immigration-arrangements-foreu-citizens-moving-to-the-uk-after-brexit (accessed October 2020).

19. GDC. Moving upstream. 2019. Available online at https://www.gdc-uk.org/about-us/our-organisation/ our-corporate-strategy-and-business-plans/movingupstream (accessed October 2020).

20. Breckenridge, A. \& Feldschreiber, P. Impact of Brexit on UK and EU Drug Regulation and Patient Access. Clin. Pharmacol. Ther. 2018; 105: 923-925. 
21. House of Commons Business, Energy and Industrial Strategy Committee. The impact of Brexit on the pharmaceutical sector: Ninth Report of Session 201719. 2018. Available at https://publications.parliament. $\mathrm{uk} / \mathrm{pa} / \mathrm{cm} 201719 / \mathrm{cmselect} / \mathrm{cmbeis} / 382 / 382 . \mathrm{pdf}$ (accessed October 2020)

22. House of Commons Exiting the EU Committee. EU Exit Analysis: Cross Whitehall Briefing. 2018. Available at https://www.parliament.uk/globalassets/ documents/commons-committees/Exiting-theEuropean-Union/17-19/Cross-Whitehall-briefing/ EU-Exit-Analysis-Cross-Whitehall-Briefing.pdf (accessed October 2020).

23. UK Government. Operation Yellowhammer. 2019. Available at https://assets.publishing.service.gov.uk/ government/uploads/system/uploads/attachment data/file/831199/20190802_Latest_Yellowhammer_ Planning_assumptions_CDL.pdf (accessed October 2020).

24. Department of Health and Social Care. How medicines, medical devices and clinical trials would be regulated if there's no Brexit deal. 2019. Available online at https://www.gov.uk/government/publications/ how-medicines-medical-devices-and-clinical-trialswould-be-regulated-if-theres-no-brexit-deal/ how-medicines-medical-devices-and-clinical-trialswould-be-regulated-if-theres-no-brexit-deal (accessed October 2020)

25. Maignen F, Berdud M, Hampson G, Lorgelly P. Public Health and Economic Implications of the United Kingdom Exiting the EU and the Single Market. 2017. Available at https://www.abpi.org.uk/media/4577/ohe-consultingpublic-health-and-economic-implications-of-the-unitedkin.pdf (accessed October 2020).

26. Kazzazi F, Pollard C, Tern P, Ayuso-Garcia A, Gillespie J, Thomsen I. Evaluating the impact of Brexit on the pharmaceutical industry. J Pharm Policy Pract 2017; DOI: 10.1186/s40545-017-0120-z.

27. European Commission. How to use the card: Employment, Social Affairs \& Inclusion. Available online at https://ec.europa.eu/social/main. isp?catld=1021\&langld=en (accessed October 2020).

28. Department of Health and Social Care, Foreign \& Commonwealth Office and Foreign, Commonwealth \& Development Office. Healthcare for UK nationals visiting the EU. 2020. Available online at https://www gov.uk/guidance/uk-residents-visiting-the-eueea-andswitzerland-healthcare (accessed October 2020).

29. Brexit Health Alliance. Briefing: Maintaining reciprocal healthcare for patients after Brexit. 2017. Available at https://www.nhsconfed.org/-/media/Confederation/ Files/Publications/Maintaining-reciprocal-healthcarefor-patients-after-Brexit.pdf (accessed October 2020).

30. Greenberg A, Jose R J. Public Health England prematurely endorses ecigarettes. BMJ 2018; DOI: 10.1136/bmj.k1262.

31. McNeill A, Brose LS, Calder R, Bauld L, Robson D. Evidence review of ecigarettes and heated tobacco products 2018: A report commissioned by Public Health England. 2018. Available at https://assets. publishing. service.gov.uk/government/uploads/system/uploads/ attachment_data/file/684963/Evidence_review_of_ecigarettes_and_heated_tobacco_products_2018.pdf (accessed October 2020).

32. House of Commons Science and Technology Committee. Ecigarettes: Seventh Report of Session 2017-19. 2018. Available at https://publications.parliament.uk/pa/ cm201719/cmselect/cmsctech/505/505.pdf (accessed October 2020).

33. European Centre for Disease Prevention and Control. ECDC's mission and main activities. 2020. Available online at https://www.ecdc.europa.eu/en/about-us/ ecdcs-mission-and-main-activities (accessed October 2020).

34. Coulthard P. Dentistry and coronavirus (COVID-19)moral decision-making. Br Dent J 2020; 228: 503-505.

35. Cancer Research UK and School of International Futures Future of clinical trials after Brexit: Final Report. 2018. Available at https://www.cancerresearchuk.org/sites/ default/files/future_of_clinical_trials_after_brexit.pdf (accessed October 2020).

36. Kings College London. Dentistry, Oral \& Craniofacial Sciences - Research Funding. 2020. Available online at https://kclpure.kcl.ac.uk/portal/en/organisations/ dental-institute(5371ed9b-7605-42a2-a51cd898c954e910)/projects.html?hesa=/dk/atira/pure/ funding/hesa/researchcouncils (accessed October 2020).

37. European Commission. Associated Countries. 2017. Available at https://ec.europa.eu/research/ participants/data/ref/h2020/grants_manual/ hi/3cpart/h2020-hi-list-ac_en.pdf (accessed October 2020).

38. Dayan M. How will our future relationship with the EU shape the NHS? 2017. Available at https://www. nuffieldtrust.org.uk/research/brexit-relationship-eushape-nhs (accessed October 2020).

39. Information Commissioner's Office. International Data Transfers. Available online at https://ico. org.uk/for-organisations/data-protection-at-theend-of-the-transition-period/data-protectionat-the-end-of-the-transition-period/the-gdpr/ international-data-transfers/ (accessed October 2020).

40. Health Education England. Advancing Dental Care: Education and Training Review - Final report. 2018. Available at https://www.hee.nhs.uk/sites/default/ files/documents/advancing_dental_care_final.pdf (accessed October 2020).

\section{Correction to: Dental core training: the trainee perspective}

The original article can be found online at https://doi.org/10.1038/s41415-020-1534-6

Author's correction note:

Education article Br Dent J 2020; 228: 782-790.

When initially published there were errors in the Results and Discussion section.

In the Results section, 'FigurWhile $47.6 \%$ of respondents felt that the SJT was beneficial to the application and ranking process, only $9.3 \%$ felt that it was fair, representable and realistic of real-life situations' should have read 'While $47.6 \%$ of respondents felt that the SJT was beneficial to the application and ranking process, only $10.9 \%$ felt that it was fair, representable and realistic of real-life situations.'

In the 'Situational judgement test' section of the Discussion, 'Previous stakeholder concern of the SJT have been declared, and although nearly half of all respondents (47.6\%) felt the SJT was beneficial to the process, 91.7\% felt it was not fair, realistic and representative of real-life situations, with one respondent commenting: "The SJT doesn't feel valuable to the process at all, given that a majority of the situations have never and would never arise"' should have read, 'Previous stakeholder concern of the SJT have been declared, and although nearly half of all respondents (47.6\%) felt the SJT was beneficial to the process, $78.66 \%$ felt it was not fair, realistic and representative of real-life situations, with one respondent commenting: "The SJT doesn't feel valuable to the process at all, given that a majority of the situations have never and would never arise".

The authors apologise for any inconvenience caused. 